\title{
PSYCHOLOGICAL VULNERABILITIES OF REMOTE WORKING INTERACTION
}

The work has been completed with the support of Ministry of Education and Science of RF(the project № 0159-2021-0001)

Bessonova Yu. V.(Institute of Psychology, Russian Academy of Sciences, Moscow, Russia)

bessonovajv@ipran.ru

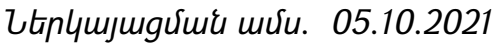

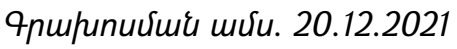

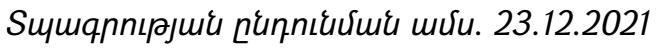

Remote work interaction is becoming the most important trend in employment management. The work-from-home online job affected not only in technical occupations who have experience in remote working. Different professions were simultaneously involved in online interaction, regardless of skills, willingness or nature of its work. Unlike humancomputer interaction, main feature of this interaction is communication between people that built outside the logic of the programming language and it is due to socio-psychological mechanisms rather than technical requirements. Online interaction depends on communication processes, cyber shadow saving / data updatability, anonymity and self-disclosure degree, etc. The comparative features of online and offline communication, the specifics of network language and communication can be considered relatively studied at the present time. However, online professional communication is beyond the focus of the researchers' attention, including the exposure of such online communication to the influence of motivation, psychological barriers, user beliefs, preferences and attitudes. User experience, affective support, and user attribution and motivation were identified as the priority predictors of remote working efficiency in the conditions of a massive and sudden shift to new working conditions.

Keywords: remote working, usability, psychological vulnerability, online interaction, communication barriers, attitudes.

DOI: https://doi.org/10.46991/SBMP/2022.5.1.031

Актуальность. Проведенные в 2020-2021 гг. исследования отношения работников и работодателей к дистанционному профессиональному взаимодействию отражают противоречивые результаты. С одной стороны, была выявлена тенденция усиления положительного отношения к удаленной работе. Если в феврале 2020 г. только 6 \% опрошенных россиян были соглас- 
ны на дистанционную работу и предпочитали работать в офисе, в начале пандемии 63\% опрошенных хотели как можно скорее вернуться в офис, а в 2021 г. уже 40\% заявили о своем позитивном отношении к удаленной работе, несмотря на то, что большинство опрошенных ранее не имело опыта дистанционной работы. В дальнейшем дистанционный формат стал рассматриваться как более предпочтительный: более 40\% опрошенных не стремятся вернуться в офис, а еще 29 \% предпочли бы совмещать в фрормате «2-3 дня офис, остальное - удаленная работа» [4].

В качестве положительных сторон дистанционной работы отмечаются: повышение продуктивности (25\% респондентов), персональной ответственности за результат (от 21 до 58\%), концентрация на основной задаче и сокращение второстепенных вопросов (50 \%), экономия времени и транспортных издержек (79\%), персональный комфорт (по разным данным от 63\% до 78 \%) [4]. Компаниям также оказалось экономически выгоднее содержать сотрудников на удаленном формате за счет сокращения трат на аренду и обеспечение офисов, поэтому все больше компаний переходит на удаленную работу как основной тип занятости.

Негативными сторонами дистанционной работы является принуждение к удаленному взаимодействию, ограничивающее гибкость и разнообразие профессиональной деятельности, необходимость быть на связи и связанная с ним «Zoom-усталость», нарушенные профессиональные ожидания [11]. Статистика В03 показывает, что работа в удаленном формате в среднем на $10 \%$ увеличивает количество рабочих часов, способствует размыванию границ между работой и личной жизнью, ведет к росту инсультов и инфарктов при переработке. Работодатели жалуются на снижение креативности сотрудников, фрормализацию общения, снижение индивидуальной ответственности сотрудников. Среди основных проблем, связанных с «удаленкой», сами работники отмечают снижение производительности труда из-за постоянного отвлечения на домашние дела, размывание границ личного и рабочего пространства, снижение согласованности командных действий, замедление бизнес процессов и принятия решений, отсутствие необходимой офисной техники, снижение дохода из-за экономии компаний на компенсациях, недостатке общения с сотрудниками, выгорание [2, 11].

Противоречивость полученных данных отражает, во-первых, содержательную неоднородность выборок: в большинстве опросов выборка респондентов предварительно не отбиралась по критериям гомогенности, в одну группу попадали люди, имеющие практический опыт удаленной работы до введения санитарных ограничений («цифровые номады», фррилансеры, представители некоторых профессий), и люди, впервые столкнувшиеся с работой в онлайн-фрормате. Переход на дистанционную работу в условиях пан- 
демии затронул не только специалистов технического профиля, имеющих опыт такого взаимодействия и готовых к эфффективному осуществлению профессиональной деятельности онлайн. Во-вторых, статистические данные отражают процесс адаптации и самих работников, и компании к удаленному формату взаимодействия: в опросах 2021 года респонденты значительно более позитивно отзываются об удаленной работе; ряд проблем, связанных с техническим обеспечение рабочего места, организацией, коммуникацией и взаимодействием в коллективе, на 2021 год оказывается решенным. Однако, приобретают остроту иные проблемы, в том числе социальные (связанные с организацией), эргономические (связанные с недостатками платфрорм для телекоммуникации), психологические.

Опосредованное дистанционное взаимодействие, как показали результаты исследований, является не столько разновидностью человек-компьютерного взаимодействия, сколько представляет собой коммуникацию между людьми и обусловлено социально-психологическими закономерностями [8]. Эффрективность и удовлетворенность дистанционного взаимодействия, однако, связывается с рядом характеристик, несводимых ни к социально-психологическим феноменам, ни к техническим показателям: в частности, проблемам безопасности общения и хранения цифрового следа, особенностям коммуникации посредством технологических решений, специфики лингвистических и паралингвистических форм онлайн-коммуникации. Поскольку указанные фракторы непосредственно сказываются на эффрективности опосредованной коммуникации, приобретает особую актуальность исследование профрессионального онлайн-общения. Большая часть проблем при профессиональном компьютер-опосредованном взаимодействии могут быть потенциально связаны с психологическими факторами как самой удаленной работы, так и взаимодействия человека с интерфейсом коммуникационных программных платформ. Поскольку эти факторы проявляются только при онлайн-взаимодействии, речь может идти о «психологических уязвимостях» потенциальных свойствах личности и психики человека, проявляющихся только под влиянием внешнего средового воздействия [7]. Компьютеропосредованное профессиональное взаимодействие, как разновидность «межличностной опосредованной коммуникации», отличается рядом особенностей, накладываемых промежуточной переменной - средой и средствами коммуникации. Влияние среды проявляется в усилении роли способа передачи информации, вовлеченности участников, ограниченности каналов передачи информации, опосредованность общения, особенности языка коммуникации и пр. [9]. Онлайн-общение меняет характер межличностной коммуникации, снижаются показатели доверия, взаимопомощи, взаимоуважения при повышении вседозволенности и эгоизма [1]. Было обнаружено, что 
эфрфективность и стиль онлайн-общения зависит, во-первых, от целей и мотивов общения, и, во-вторых, находится в тесной взаимосвязи с адаптивностью студентов к новым психологическим условиям, принятием образа себя, с ощущением эмоционального комфорта [6], эффектом присутствия и включенностью в онлайн-коммуникацию [3].

Влияние средств коммуникации относится не только к предметной области эргономики, но затрагивает особенности профессионального менталитета, определяющие степень принятия пользователем новой технологии. Было установлено, что в структуру менталитета профессионала входят, помимо когнитивного и поведенческого компонентов, обусловленных профессиональной квалификацией и опытом, эмоциональный и ценностно-мотивационный компоненты, связанные с особенностями отношения и мировоззрения. Ценностный компонент включает негласные, неписаные правила поведения, ожидания и установки.

Существенные изменения условий труда, к которым может относиться переход на удаленную работу, меняют привычный стиль профессионального общения, систему психологического рабочего контракта человека (ожиданий и долженствований) и затрагивают структуру когнитивных установок личности. Имеющиеся у работника имплицитные когнитивные установки проявляются при снижении сознательного контроля в новых, непривычных, затрудненных условиях либо условиях, связанных с дополнительной нагрузкой и ответственностью решаемой задачи [10], и отражают роль преобладания эвристик над аналитикой [12], влияние эмоционального компонента принятия решений [5]. Именно ценностный компонент менталитета оказывает существенное влияние на надежность профессиональной деятельности, являясь триггером, меняющим и направляющим стиль профессионального взаимодействия.

Цель и гипотеза исследования. С целью более подробного изучения этих проблем было проведено пилотажное исследование эффективности и надежности дистанционного профессионального взаимодействия и психологических фракторов, влияющих на эффективность профессиональной онлайнкоммуникации (имплицитных неосознаваемых установок, когнитивных искажений, мотивов и целей). Первая гипотеза состояла в предположении, что удовлетворенность средством компьютер-опосредованного взаимодействия является существенным фактором снижения эффективности дистанционного взаимодействия специалистов. Вторая гипотеза - выраженность психологических уязвимостей пользователей зависит в большей степени от отношения к интерфейсу средств коммуникации, нежели от отношения к дистанционному формату профессионального взаимодействия. 
Выборка. Объем выборки составил 30 респондентов, обеспечивалась гомогенность выборки - были обследованы представители гуманитарной профессии (преподаватели), имеющие опыт взаимодействия с разными платформами онлайн-коммуникации. При составлении листа праймов для методики Имплицитного ассоциативного теста (Greenwald, McGhee, Schwartz, 1998) было привлечено дополнительно 5 экспертов.

Методы и методики исследования. Отношение к дистанционному формату профессионального взаимодействия и психологические уязвимости оценивались с помощью интервью на основе приемов когнитивно-поведенческой терапии. Для выявления неявных когнитивных установок использовался Имплицитный ассоциативный тест (Greenwald, McGhee, Schwartz, 1998). Отношение пользователей к платформам онлайн-коммуникации оценивалось с помощью методики The Post-Study System Usability Questionnaire (PSSUQ). Эфффективность профессиональной деятельности оценивалась по степени профессиональной востребованности: количеству учеников, записавшихся на курсы, и количеству учебных часов за 2019-2020 и 2020/2021 учебный год. Дополнительно регистрировались социо-демографические данные (пол, возраст, стаж), пользовательский опыт.

Результаты и их обсуждение. На первом этапе исследования был проведен опрос респондентов степенью удовлетворенности компьютер-опосредованным профессиональным взаимодействием на текущий момент: $27 \%$ респондентов были полностью удовлетворены, $41 \%$ - скорее удовлетворены, $15 \%$ - скорее неудовлетворенны, 17\% - полностью не удовлетворены. Оценка эффективности профессиональной деятельности показала прирост профессиональной нагрузки в среднем на $13 \%$ по сравнению с предыдущим учебным годом. Не было установлено взаимосвязи между уровнем удовлетворенности дистанционным взаимодействием и ее эффрективностью (профессиональной востребованностью).

Далее мы проверили предположение, как удовлетворенность компьютер-опосредованным профессиональным взаимодействием связана с отношением к средствам этого взаимодействия (привычным пользователю сервисам). Мы попросили респондентов оценить по тесту PSSUQ степень удобства, функциональности, комфорта сервисов онлайн-коммуникации, которые они используют в повседневной профессиональной деятельности. Была подтверждена взаимосвязь между показателями удовлетворенности профессиональным взаимодействием $и$ уровнем удобства используемого сервиса в полярных группах - наиболее и наименее удовлетворенных. Гипотеза о важности удовлетворенности средствами опосредованной коммуникации получила частичное подтверждение. Пользовательский опыт и привычность средства онлайн-коммуникации повышают удовлетворенность 
дистанционным форматом профессиональной деятельности за счет повышения удовлетворенности от интерфейса средств коммуникации. Негативные эмоции пользователей были связаны с совмещением задач (необходимостью осваивать средства коммуникации и выполнять непосредственные профессиональные обязанности), ненадежностью сервиса онлайн-коммуникации (сбои, отказы), освоенностью и привычностью сервиса (частотой использования функций онлайн-платформы).

Результаты имплицитного ассоциативного теста показали, что дистанционное взаимодействие наиболее часто ассоциируется с такими характеристиками, как: независимость, свобода, комфорт, безопасность, самоуважение. Интервью с элементами когнитивно-поведенческих техник позволило проанализировать основные профессиональные ситуации («что происходит?»), эмоциональные реакции («как вы к этому относитесь?»), когнитивные суждения («что вы в этот момент думали? почему? что это значит для вас?») и поведенческие проявления («что вы делали? помогло ли достичь цели?»). Эмоциональная оценка событий позволила выявить для каждой из профессиональных ситуаций наиболее характерные эмоции и перечень факторов, связанных с возникновением этих эмоций. К примеру, негативные эмоции при проведении лекционного занятия в дистанционном фрормате выражались в страхе возникновения технических сбоев трансляции, неуверенности в правильности действий, страхе низкой оценки собственного профессионализма учениками, дезориентации. Ситуационными факторами, способствующими возникновению данных эмоций, были невозможность контроля внимания учеников, отсутствие обратной связи, асинхронность общения, сохранение цифрового следа и отсутствие конфиденциальности ситуации, технические и технологические ограничения сервисов онлайн-коммуникации, ограниченность канала взаимодействия, необходимость делегировать студентам большую самостоятельность в освоении материала. Нерациональные установки, выявленные у респондентов, были связаны с повышенными требованиями к себе как профессионалу и особенностями мотивации (выраженностью мотива конкуренции, страха неудач). В условиях повышенной психологической нагрузки (публичность, нонконфиденциальность) при выполнении дополнительных задач (обеспечения трансляции, контроль студентов) проведение дистанционной лекции вызывало более сильный стресс у преподавателей. Поведенческие реакции проявлялись либо в чрезмерно высоком, либо чрезмерно низком доверии технике.

Выводы. Синтез диагностических методов когнитивно-поведенческой терапии, юзабилити и поведенческих тестов оценки атрибуции позволит выявить психологические уязвимости компьютер-опосредованного профессионального взаимодействия. Результаты подтверждают, что удовлетворенность 
работника дистанционным фрорматом взаимодействия и его оценка эффективности такого взаимодействия в значительной степени связана с удовлетворенностью средствами, обеспечивающими онлайн-коммуникацию, освоенностью этих средств и соответствием их технических возможностей решаемым задачам. Субъективная оценка взаимодействия с интерфейсом связана с эмоциональной стороной, ожиданиями и установками пользователя. Одной из задач будущих исследований может являться оценка помехоустойчивости профессиональной онлайн-коммуникации в затрудненных и осложненных условиях (к примеру, при дефиците времени или неустойчивом подключении).

\section{Литература}

1. Блинова Н.М. Интернет-коммуникация: специфика опосредования межличностных отношений // Известия Иркутского государственного университета. Серия «Психология». 2014. Т.9. с. 19-22.

2. Ганьжа Д. Как оценить эффеектиность сотрудников на удалённой работе//Управляем предприятием. 27 ноября 2020. https://upr.ru/article/kak-otsenit-effektivnost-sotrudnikov-na-udalennoyrabote/ Дата обращения: 21.09.2021.

3. Золотухин С.А. Типы взаимодействия С обучающимися в компьютерно-опосредованном обучении// Современные исследования социальных проблем (электронный научный журнал), Modern Research of Social Problems, №5(25), 2013. DOI: 1012731/2218-74052013-5-22.

4. Как оценили удаленную работу офисные сотрудники // ABD architects, 25 июня 2020. https://vc.ru/office/137349-kak-oceniliudalennuyu-rabotu-ofisnye-sotrudniki (Дата обращения: 21.09.2021).

5. Канеман Д. Думай медленно... Решай быстро. М.: АСТ, 2014.

6. Лукина Н.А. Психологические особенности опосредованного Интернетом межличностного общения студентов. Дисс., канд.психол.наук. Самара, 2013.

7. Обознов А.А., Занковский А.Н., Бессонова Ю.В. Понятие эргономической уязвимости человекомашинных интерфейсов// Институт психологии Российской академии наук. Организационная психология и психология труда. 2020. Т.5. №2. с. 112-126. DOI: https://doi.org/10.38098/ipran.opwp.2020.15.2.006.

8. Розина И.Н. Педагогическая компьютерно-опосредованная коммуникация: теория и практика. М.: Логос, 2005. 
9. Романова М.В. Компьютерное общение как вид опосредованного общения//Теоретическая и экспериментальная психология. 2009. Т.2. №4. c. 59-70.

10. Fazio, R. H.; Towles-Schwen, T. The MODE model of attitude-behavior processes. In: Chaiken, S.; Trope, Y., editors. Dual process theories in social psychology. New York: Guilford; 1999. pp. 97-116.

11. Hickman A., Kluch S. Don't Mistake Forced Remote Work for a Job Perk (October 26, 2020). Gallup Analytics, Workplace.

https://www.gallup.com/workplace/322337/don-mistake-forced-remotework-job-perk.aspx. Дата обращения: 21.09.2021.

12. Petty, R.E.; Cacioppo, J.T. The elaboration likelihood model of persuasion. In: Berkowitz, L., editor. Advances in experimental social psychology. Vol. 19. San Diego, CA: Academic Press; 1986. pp. 123-205.

\section{ПСИХОЛОГИЧЕСКИЕ УЯЗВИМОСТИ ДИСТАНЦИОННОГО ПРОФЕССИОНАЛЬНОГО ВЗАИМОДЕЙСТВИЯ}

Исслед. выполнено по Государственному заданию Минобрнауки РФ, проект № 0159-2021-0001

Бессонова Ю. В. (ФГБУН Институт психологии РАН, Москва, Россия)

Компьютерно-опосредованное взаимодействие становится важнейшим трендом в организации труда. Переход на удаленную работу в условиях пандемии затронуло не только специалистов технического профиля, имеющих опыт такого взаимодействия и готовых к эффрективному осуществлению профессиональной деятельности онлайн. В компьютер-опосредованное взаимодействие оказались одномоментно вовлечены представители различных профессиональных областей, вне зависимости от уровня подготовленности и характера осуществляемой деятельности. Содержательное отличие такого взаимодействия заключается в том, что, в отличие от взаимодействия человеккомпьютер, оно представляет собой коммуникацию между людьми, строится вне логики языка программирования и обусловлено скорее социально-психологическими механизмами, нежели техническими требованиями. Исследования показали особенности компьютер-опосредованного взаимодействия в зависимости от таких его характеристик, как синхронность / асинхронность общения, сохранность цифррового следа / обновляемость, анонимность, степень самораскрытия и пр.

Относительно изученными в настоящее время можно считать сравнительные особенности онлайн и офлайн общения, специфику сетевого языка и коммуникации. Однако за рамками внимания исследователей 
оказалась сфера именно профессионального общения онлайн. В том числе подверженность такого профессионального онлайн общения влиянию мотивации, психологических барьеров, убеждений, предпочтений и установок пользователей. Эмоции, атрибуции и мотивация пользователя были выявлены нами в качестве основных предикторов эффективности удаленной работы в условиях массового и внезапного перехода к новым организационным условиям труда.

Ключевые слова: психологические уязвимости, юзабилити, удаленная работа, онлайн взаимодействие, барьеры коммуникации, аттитьюды. 